\title{
SELECTIVE SYMPATHETIC DENERVATION OF THE RABBIT DUCTUS DEFERENS USING 6-HYDROXYDOPAMINE
}

\author{
J. P. POLIDORO, R. GULVER, S. THOMAS \\ AND F. G. GREENSLADE \\ Ortho Research Foundation, Raritan, New Fersey 08869, U.S.A.
}

(Received 28th Fanuary 1974)

The male reproductive tract receives a rich adrenergic innervation (Sjöstrand, 1965; Hodson, 1965; Norberg, Risley \& Ungerstedt, 1967). Previous attempts to achieve denervation of the sympathetic supply to the ductus deferens required drastic surgical stripping of the serous coat and mesenteric attachments (Birmingham, 1970; Birmingham, Paterson \& Wojcicki, 1970). Recently, Eddy \& Black (1973) have shown that selective sympathectomy of the rabbit oviduct can be achieved with 6-hydroxydopamine. The present study was designed to evaluate this denervation method in the rabbit ductus deferens.

Thirty-eight mature Dutch-belted male rabbits were utilized in this study. The perfusion method of Eddy \& Black (1973) was modified for application to the ductus deferens. Varying concentrations of 6-hydroxydopamine hydrobromide (6-OH-DA: Regis Chemical Co.) in $0.9 \%$ sterile ascorbic saline $(0.5$ $\mathrm{mg}$ ascorbic acid $/ \mathrm{ml}$ ) were individually perfused through one ductus deferens of each rabbit (Table 1). The contralateral ductus, which was not perfused, served as a control.

Under sodium pentobarbital anaesthesia, the epididymal end of the ductus was isolated through a small incision in the scrotum. The blunted tip of a 20-gauge needle, attached to a 43-cm length of Silastic tubing (i.d. 0.030 in., o.d. 0.065 in., Dow Corning), was introduced into the ductus and secured with a ligature of 0 -silk suture. Care was taken to isolate the vascular system from the area of insertion. A $2 \cdot 0-\mathrm{ml}$ syringe, containing the $6-\mathrm{OH}-\mathrm{DA}$ solution, was connected to the cannula and placed in a Harvard infusion/withdrawal pump (Model 906). Following completion of a low mid-ventral laparotomy, an 8.0-cm length of P.E. 60 polyethylene tubing (i.d. 0.030 in., o.d. 0.048 in., Clay Adams) was inserted into the ampullary end of the ductus at the base of the bladder and secured with 0 -silk suture. This facilitated collection of the 6-OH-DA perfusate.

The ascorbic saline alone or the 6-OH-DA was perfused at a rate of $6.5 \mu \mathrm{l} /$ $\min (400 \mu \mathrm{l}$ total) for approximately $1 \mathrm{hr}$. The ductus was then flushed with $200 \mu \mathrm{l}$ sterile ascorbic saline at a rate of $20 \mu \mathrm{l} / \mathrm{min}$, the scrotal and abdominal incisions were sutured and the animals were returned to their cages.

At autopsy 1 to 4 weeks later, the ductus deferentes were removed and trimmed of supporting mesentery. To determine local and systemic denervation, 
segments of both the treated and the untreated contralateral control ductus deferens were prepared in order to demonstrate microscopically the presence of fluorescent norepinephrine (Falck, 1962; Falck, Hillarp, Thieme \& Torp, 1962; Falck \& Owman, 1965). Simultaneously, segments of the ductus from additional untreated rabbits were processed as a procedural check for success of the histochemical assay. The segments were individually frozen (Lipshaw tissue capsules) in liquid nitrogen-cooled isopentane (2-methyl-butane) and were transferred to a Thermovac freeze-drier $\left(-55^{\circ} \mathrm{C}\right)$ for 3 to 5 days. After freeze-drying, the tissue was exposed to formaldehyde vapour (generated from paraformaldehyde: $70 \%$ relative humidity) in an incubation oven $\left(80^{\circ} \mathrm{C}\right.$ ) for $1 \mathrm{hr}$. The vacuum-infiltrated samples $(30 \mathrm{~min})$ were embedded in Paraplast and sectioned at $9 \mu \mathrm{m}$. Sections were mounted with Entellan (Brinkman

Table 1. Scheme for perfusion of rabbit ductus deferens with 6-hydroxydopamine in ascorbic saline

\begin{tabular}{c|c|c|c|c|c|c|c|c}
\hline & \multicolumn{1}{|c}{ Group } \\
\cline { 2 - 8 } & 1 & 2 & 3 & 4 & 5 & 6 & 7 & 8 \\
\hline $\begin{array}{c}\text { Total 6-OH-DA } \\
\text { perfused (mg) }\end{array}$ & $\begin{array}{l}0^{*} \\
\text { No. of rabbits }\end{array}$ & $\begin{array}{c}1 \cdot 0 \\
2\end{array}$ & $\begin{array}{l}3 \cdot 0 \\
2\end{array}$ & $\begin{array}{c}5 \cdot 0 \\
2\end{array}$ & $\begin{array}{c}7 \cdot 0 \\
2\end{array}$ & $\begin{array}{c}10 \cdot 0 \\
4\end{array}$ & $\begin{array}{c}20 \cdot 0 \\
4\end{array}$ & $\begin{array}{c}50 \cdot 0 \\
1\end{array}$ \\
\hline
\end{tabular}

* Ascorbic saline only $(0.5 \mathrm{mg}$ ascorbic acid $/ \mathrm{ml} \mathrm{0.9 \%}$ sterile saline).

Instrument Co., Westbury, N.Y.), a non-fluorescent mounting medium. Fluorescence was generated by an Opti-Quip DC power source containing an Osram HBO 200-W bulb and tissues were examined using a Leitz Ortholux microscope which contained a KP490 exciter filter and a K530 barrier filter. A Leitz D 0.80 dark-field condenser aided the detection of fluorescent nerve endings in the absence of immersion oil.

In addition, segments of control and treated ductus were fixed in formalin and subsequently stained with haematoxylin and eosin to determine any 6-OH-DA-induced changes in histology.

The effects of the surgical method on norepinephrine fluorescence before the 6-OH-DA perfusion was assessed in nineteen rabbits. Perfusion of saline, with or without ascorbic acid, was found to result in a marked decrease in norepinephrine fluorescence in rabbits killed 1 to 3 weeks later. Shorter perfusion times did not alleviate this effect. A systematic study of the surgical procedure indicated that cannulation and ligation, cannulation only or ligation only was responsible for varying degrees of reduced fluorescence. Recovery of fluorescence was virtually complete 4 weeks after any of the sham operations. In order, therefore, to separate the surgical and 6-OH-DA effects on denervation, the 6-OH-DA perfused animals were killed no earlier than 4 weeks after surgery.

It is apparent that the ductus deferens can be selectively denervated by 6-OH-DA (Pl. 1, Figs 1 and 2). The histochemical results were similar to those of Eddy \& Black (1973), indicating that the smooth musculature of the oviduct and ductus deferens reacts similarly to the 6-OH-DA perfusate. No alterations 


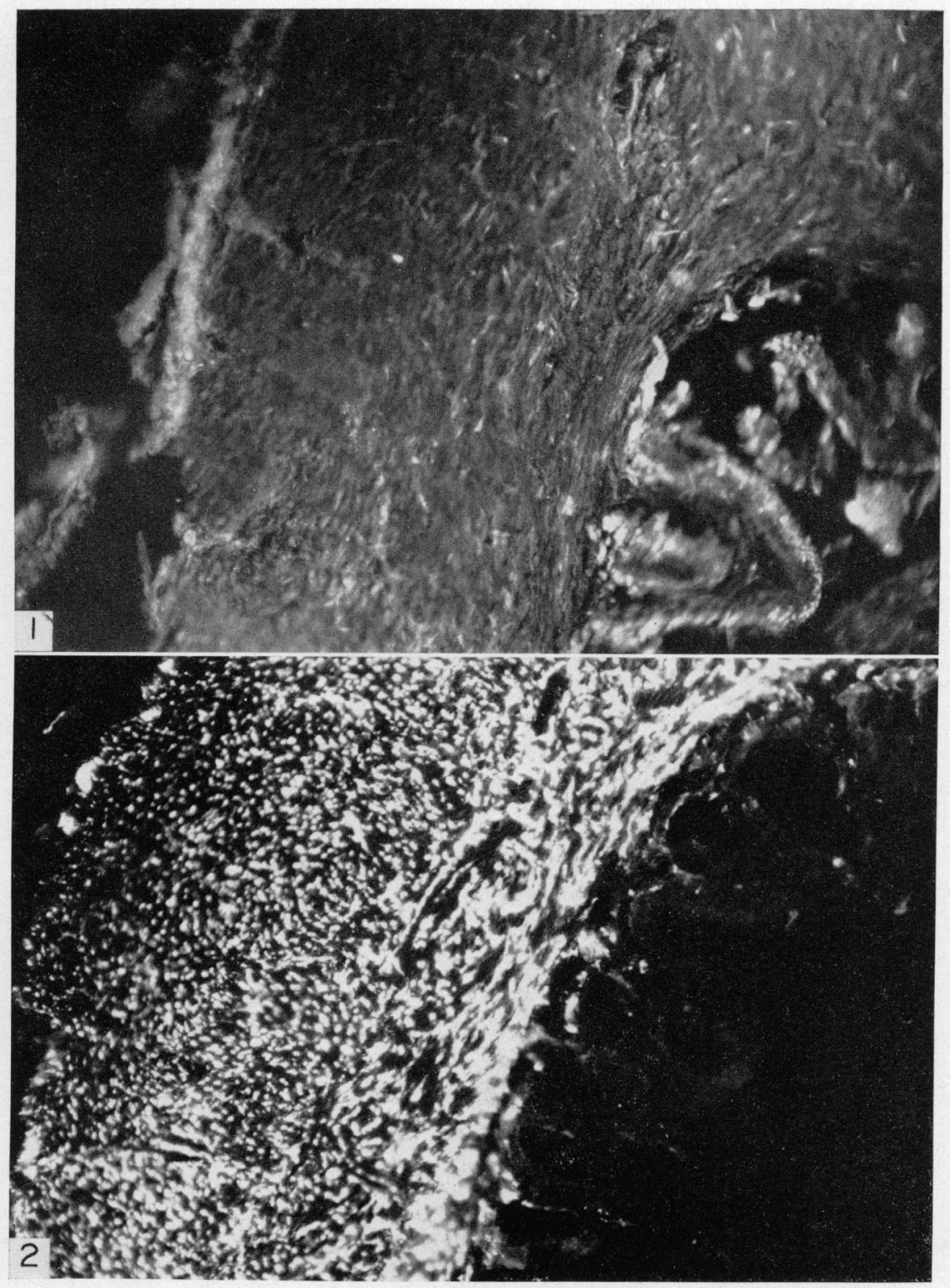

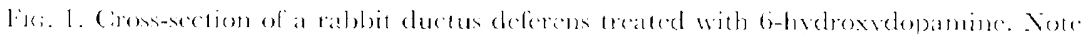

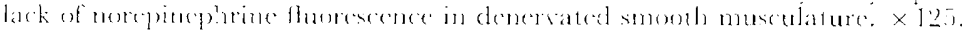

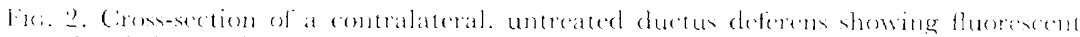

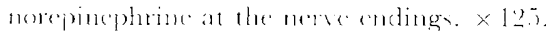


in the normal histology of the ductus were noted following the 6-OH-DA perfusion.

No significant reduction in fluorescence was observed 4 weeks after perfusion with ascorbic saline alone.

Various degrees of incomplete adrenergic denervation occurred in each of the groups treated with doses of $1.0,3 \cdot 0,5.0$ and $7 \cdot 0 \mathrm{mg} 6-\mathrm{OH}-\mathrm{DA}$. Distinct, weak fluorescence was often noted in the longitudinal smooth muscle layer but was usually absent in the inner circular layer.

With 10-, 20- and 50-mg doses, complete absence of fluorescence was observed on the treated side. A possible systemic effect of the 6-OH-DA was first observed with a $20-\mathrm{mg}$ dose; there was a reduction in the intensity and density of norepinephrine fluorescence in the contralateral ductus in two rabbits. The systemic effect became more apparent with a 50-mg dose of 6-OH-DA. Optimal denervation of the ductus deferens without a systemic effect on the contralateral side appears, therefore, to be achieved with a $10-\mathrm{mg}$ dose of 6-OH-DA. This is a slightly higher dose than that required to denervate the oviduct (Eddy \& Black, 1973).

As was previously shown with the oviduct (Eddy \& Black, 1973), 6-OH-DA had little effect on the fluorescence of perivascular nerves, which was significantly reduced in the ductus only with the higher doses of 6-OH-DA. The fluorescence of 5-hydroxytryptamine in the epithelial cells of the ductus did not appear to be depleted by 6-OH-DA at any of the dose levels studied. Although the presence of 5-hydroxytryptamine in the epithelial cells of the ductus occurred frequently, its physiological rôle is not known.

The use of 6-OH-DA, perfused transluminally through the ductus should provide a new method for selectively denervating the adrenergic nervous system, and prove useful in the elucidation of the neuromuscular interrelationships of the ductus deferens.

The authors wish to thank Dr C. A. Eddy, University of Texas at San Antonio, for his comments and suggestions. Our gratitude is extended to Mrs Carol Taraschi and Dr R. F. McConnell for their assistance in the preparation and evaluation of the general histology. A special word of thanks is extended to Dr L. Kraft and Dr D. W. Hahn for their comments and to Mrs S. Moore for typing the manuscript.

\section{REFERENGES}

Brrmingham, A. T. (1970) Sympathetic denervation of the smooth muscle of the vas deferens. $\mathcal{F}$. Physiol., Lond. 206, 645.

Birmingham, A. T., Paterson, G. \& Wojcicki, J. (1970) A comparison of the sensitivities of innervated and denervated rat vasa deferentia to agonist drugs. Br. F. Pharmac. Chemother. 39, 748.

EDDY, C. A. \& BLACK, D. L. (1973) Chemical sympathectomy of the rabbit oviduct using 6-hydroxydopamine. F. Reprod. Fert. 33, 1.

FALCK, B. (1962) Observations on the possibilities of the cellular localization of monoamines by a fluorescent method. Acta physiol. scand. 56, Suppl. 197.

Falck, B., Hillarp, N. A., Thieme, G. \& Torp, A. (1962) Fluorescence of catecholamines and related compounds condensed with formaldehyde. F. Histochem. Cytochem. 10, 348.

FaLck, B. \& OWMan, C. (1965) A detailed methodological description of the fluorescence method for the cellular demonstration of biogenic monoamines. Acta Univ. lund. 7, 1. 
Hodson, N. (1965) Sympathetic nerves and reproductive organs in the male rabbit. F. Reprod. Fert. 10, 209.

Norberg, K. A., Risley, P. L. \& Ungerstedt, U. (1967) Adrenergic innervation of the male reproductive ducts in some mammals. I. The distribution of adrenergic nerves. Z. Zellforsch. 76, 278.

Sjöstrand, N. O. (1965) The adrenergic innervation of the vas deferens and the accessory male genital glands. Acta physiol. scand. 65, Suppl. 257. 